\title{
Waste transformation of plastic bags by wet polymer binding
}

\author{
Tefy Raoelivololona ${ }^{1, *}$, Mamiharijaona Ramaroson ${ }^{2}$, and Chrysostome Raminosoa ${ }^{3}$ \\ ${ }^{1}$ Ecole Supérieure Polytechnique d'Antsiranana - BP O Antsiranana 201 - Madagascar \\ ${ }^{2}$ Ecole Supérieure Polytechnique d'Antsiranana - BP O Antsiranana 201 - Madagascar \\ ${ }^{3}$ Ecole Supérieure Polytechnique d'Antsiranana - BP O Antsiranana 201 - Madagascar
}

\begin{abstract}
Since twenty years, Madagascar suffered, by the advanced level of pollution due to the proliferation of plastic bags. They are always discarded in nature and constitute an increasingly important visual and environmental pollution in cities. And because they are easily carried and deposited everywhere by the wind, it has more negative consequences on the environment and thus on the health of the population. Plastics are among the most persistent pollutants and the problem appears when they reach the waste stage. The degradation of these plastic bags requiring more than four centuries, so the search for solutions for the use of these products is very solicited to preserve the environment. That's why our research is consecrated into the transformation of plastic bags into pavers or bricks at a lower cost. The combustion of plastics releases large quantities of thick and toxic fumes. So, to avoid this phenomenon, our so-called "wet" process consists in heating a mixture of a Rich Carbon of Waste Element (RCWE), fusing the plastic bags as a binder and adding the sand as agglomerate. We obtain a quantity of product 3 times higher than the quantity of plastic bags used (to have $60 \mathrm{~kg}$ of product, we need $20 \mathrm{~kg}$ of plastic bags) unlike the other processes providing $5 \mathrm{~kg}$ of product for $20 \mathrm{~kg}$ of plastic bags, ie the plastic is reduced by $1 / 4$. The rest of the study focused on the melting temperature of the plastic bag in the RCWE which is approximately $110^{\circ} \mathrm{C}$, the proportions between the RCWE and the plastic bag for the optimization of the cost of energy : we showed that the energy is optimal for a proportion of half $(100 \mathrm{~g}$ of RCWE for $50 \mathrm{~g}$ of plastic), the proportions between plastics and sand (binder and agglomerate) : by weight, the binder must always be less than the agglomerate (the result is optimal in the proportion of agglomerate - binder $80-20$ ), the mechanical behavior : the result shows that when the quantity of plastics is the higher, the maximum stress is high, but the plastic area is low. The product is among the ductile materials, the property of which a material can permanently deform before breaking (an important factor for the deformation of materials), the permeability, and the adhesion test with the rubber.
\end{abstract}

\section{Introduction}

Climate change is one of the consequences of environmental degradation. For decades, ecologists have been concerned about the future of our planet, sustainable development and the species existing in it.

In addition, the number of the population continues to increase. Humanity currently is about 7 billion.

The evolution of technology and inventions favor man to degrade the quality of the environment.

The development of a galloping demographic in the regions and in the secondary cities has led to enormous problems in terms of hygiene and sanitation. The increasing insalubrity in almost all these cities is due to uncontrolled town planning and the proliferation of spontaneous neighborhoods. This situation has negative consequences for the living environment of the population. Today, the current situation in cities in most African countries with regard to solid and liquid waste is incompatible with the improvement of the health status of populations, environmental health and the protection of the environment. And this demographic growth also demands an overproduction of the utilitarian products and necessary on the daily life of each person, most of which are not degradable. The use of these nondegradable products on our planet quickly leads to the destruction of the environment. Moreover, these products are used in various fields for packaging, in particular in the food industry.

Currently, the search for solutions for the use of these products is solicited to preserve the environment. Incineration is not a sustainable option for dealing with waste [17]. Less energy is generated from burning the plastic than was used to make it, and incineration also means that the carbon contained within it is emitted as $\mathrm{CO} 2$ - a greenhouse gas. Toxic substances are also emitted, and large amounts of solid wastes are produced as slag, ash, filter residues and neutralization salt residues. Part of this needs to be disposed of as hazardous waste. One of the solutions is "Recycling".

\footnotetext{
*Corresponding author : vololonatefy@gmail.com
} 
Current common polymer waste recycling methods, mechanical recycling and energy recovery, have drawbacks such as labor intensive sorting and atmospheric pollution.

We quote here a method of recycling PET requiring a machine called a twin-screw extruder [16], which has high throughput. A lot of polymer can be processed in a very short time. The extruder melts the PET and creates very thin films. But the cost remains high.

In [17], he tell about the U.S. Department of Energy on-going research on plastics recycling. This report highlights new approaches to chemical recycling. Recycling of plastics can be costly and difficult because of constraints on waste contamination and inadequate separation prior to recycling. Chemical recycling could remove some of those restraints.

Research sponsored by the U.S. Department of Energy's Office of Industrial Technologies at the National Renewable Energy Laboratory has led to the development of a new process based on the pyrolysis of certain waste streams. This process retrieves monomers, the basic building blocks of a polymer, and high-value chemicals that are sufficiently pure to use in making new plastics. The advantage of this process is that the waste plastics do not have to be separated ahead of time, thereby eliminating a labor-intensive step in current processes. It also will reduce the cost of the monomers and chemicals and will reduce consumption of petroleum, the source of chemical feedstock used to produce plastics.

One of the problems in all bibliographies is that in order to have a unit of product, it takes 3 times of plastic.

During this study we focused our research on plastic bags, which are used in the manufacture of briquettes or urban pavements. Indeed, our work aims to harmonize the development of the urban infrastructure and the ecological problem. The aim of this work coincides with these problems because it concerns the "Recycling of plastic bags to make a binder for the manufacture of briquettes or urban pavers".

\section{Production and consumption of plastic bags in world}

The average increase in worldwide production and consumption of plastic bags has been around 9\% per year since its introduction in 1950. Total world production increased from about 1.5 million tones in 1950 to 260 million tones in 2007 [5].

Here is a diagram showing the evolution of production of plastics in the world.

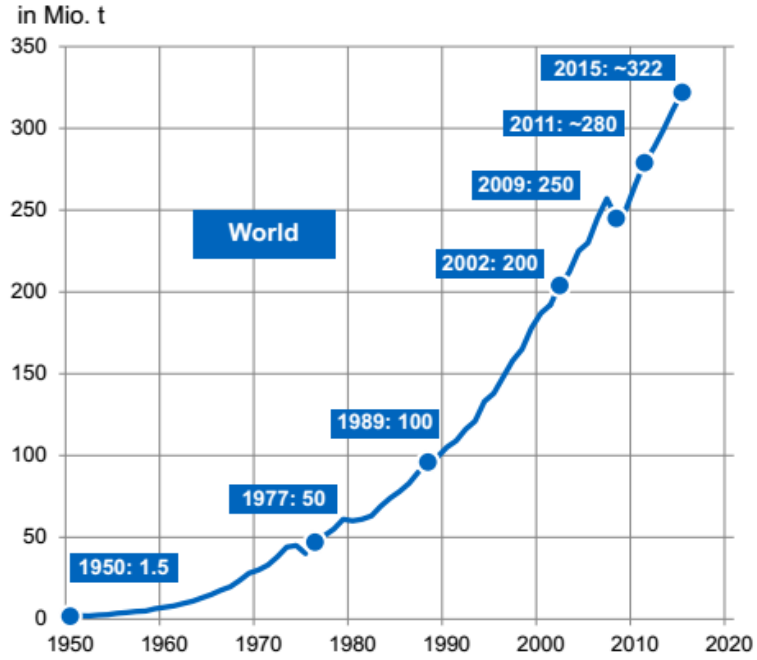

Fig. 1. World plastics production 1950 - 2015

In the world, all the existing domains cannot escape the use of the plastic bag because of its minimal cost or it is very reliable for its use. The quantity of plastic bag thrown has been estimated to $2 \mathrm{~kg}$ per year per inhabitant.

For Madagascar, the production of the plastic bag is carried out by several companies. SFOI, SACOPLAST, PLASTALLIANCE, SMTP, ENDUMA, COMEPLAST. Daily production is estimated at around 50 tones / month.

\section{Ecological and problem consequence}

The proliferation of plastic packaging bags, discarded indiscriminately in the nature by their users, constitutes a growing visual and environmental pollution in the cities. And as they are very light, they are easily carried away by the wind, and are deposited everywhere, on the branches of trees, on the thorns, ...

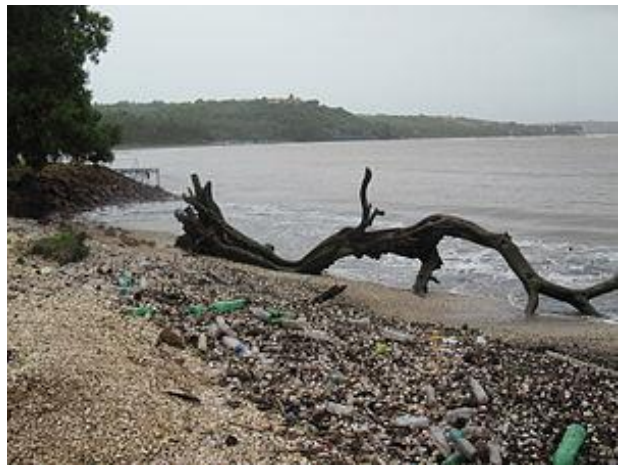

Fig. 2. Visual pollution

But the most dangerous problem is at the level of health. Plastic bags clog piping systems and lead to stagnant water that promotes malaria. 


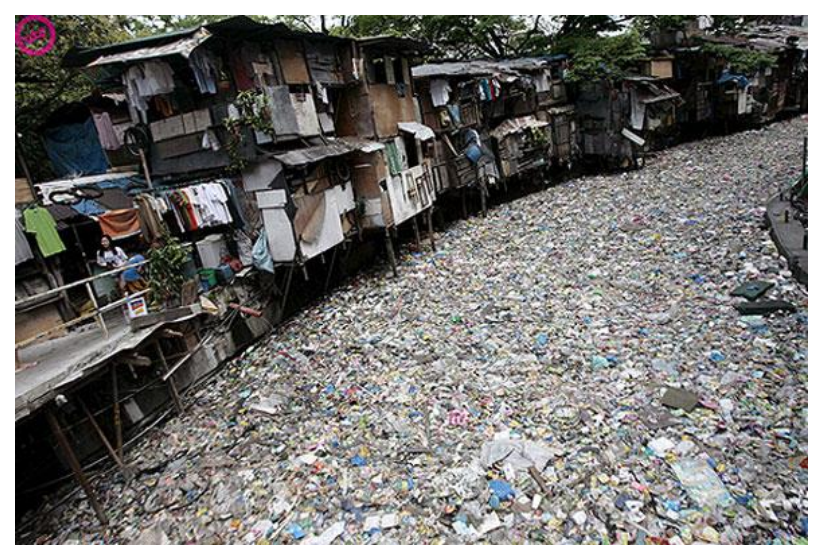

Fig. 3. Infrastructure problem

\section{Recycling}

Recycling is a process for the treatment of waste (industrial waste or household garbage). That process permits to reintroduce, in the production cycle of a product, materials that made up a similar product that has reached the end of its life, or manufacturing residues.

There are three main families of recycling techniques: chemical, mechanical and organic.

○ Chemical : recycling uses a chemical reaction to treat waste, for example to separate certain components.

- Mechanical : recycling is the transformation of waste by means of a machine, for example to grind.

- Organic : recycling consists, after composting or fermentation, of producing fertilizers or fuel such as biogas

The purpose of recycling is to :

○ Reduce the volume of waste and the pollution it would cause

- Preserve natural resources, since recycled material is used instead of the one that should have been extracted.

- Produce new material for use with recyclable materials

In our case, the goal is to produce a binder to make urban pavers or briquettes to improve the infrastructure of a city or a home at lower cost.

\section{Method of manufacturing}

To produce a binder from plastic bags, several recyclers proceed by incineration which emits a toxic and carcinogenic extreme gas. And this toxicity of plastic (probably containing impurities because unwashed) is added to the natural toxicity of smoke which has serious consequences on health. The respiration of this smoke leads to allergies of all kinds as well as respiratory insufficiency.

To give an ecological dimension to everything we do, we have proceeded with the wet processing, which did not produce smoke. It is the specificity of our development It is a matter of dissolving plastic bags made of polyethylene in a solvent which is also a Carbonous Element Waste that we call DREC.

The principle is to find a well-defined stoichiometric composition of plastic bag and the DREC to reveal a eutectic transformation whose dissolving temperature is lower than the melting temperature of polyethylene $\left(135^{\circ} \mathrm{C}\right)$ in order not to create toxic fumes.

\subsection{Product optimization}

To obtain the best product at a lower cost, the study of the binder is essential and necessary for the smooth running of the project.

The preparation of our mixture is simple and does not require much operation. The table 1 below shows the comparison between our processes and that practiced by the existing recyclers.

Table 1. Comparison of procedure

\begin{tabular}{cc}
\hline our procedure & other procedure \\
\hline Sorting & Sorting \\
Melting & Washing \\
& Crushing \\
& Melting \\
\hline
\end{tabular}

Thanks to this table we can immediately say that we save time and manpower.

In addition, in order to have a $5 \mathrm{~kg}$ binder, existing recyclers require $20 \mathrm{~kg}$ of plastic bag, ie a $75 \%$ reduction [8]. So they need a large amount of plastic bag to make several products.

With our process, we obtained a 3 times higher binder of the amount of plastic bag used. For example, to have $60 \mathrm{~kg}$ of binder it is enough to have $20 \mathrm{~kg}$ of plastic bag. Indeed, the solubility of the polyethylene at the eutectic temperature of the mixture is due to the rupture of the molecular bond of the polyethylene by the electrostatic force. The figure below shows the product of the eutectic mixture.

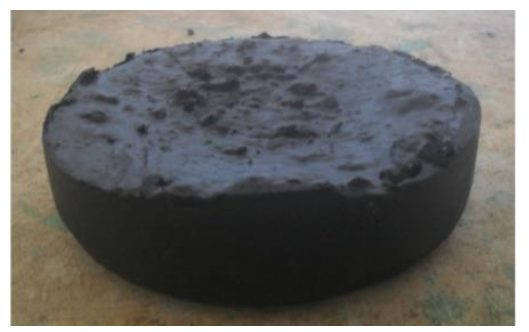

Fig. 4. The solidified eutectic binder

The energy required to dissolve $50 \mathrm{~g}$ of plastic bag is much lower compared to the incineration process. Indeed, the temperature level to be reached for the eutectic $\left(110^{\circ} \mathrm{C}\right.$. $)$ is lower than the melting temperature of the polyethylene $\left(135^{\circ} \mathrm{C}\right)$. 


\subsection{Mechanical characteristic of the binder}

To know the mechanical behavior of our binder, we have made standardized traction specimens. The traction tests were carried out on the INSTRON 4302 traction machine at the Materials Laboratory of the High School Polytechnic of Antsiranana (ESPA/UNA, MADAGASCAR). The following table summarizes the measured characteristics.

Table 2. Mechanical characteristics of the eutectic binder

\begin{tabular}{cccc}
\hline $\operatorname{Re}\left[\mathrm{N} / \mathrm{mm}^{2}\right]$ & $\mathrm{Rm}\left[\mathrm{N} / \mathrm{mm}^{2}\right]$ & $\mathrm{E}[\mathrm{GPa}]$ & $\mathrm{A} \%$ \\
\hline 1.2 & 1.8 & 0.046 & 125.4 \\
\hline
\end{tabular}

\subsection{Use of the binder for making paves}

To make paving stones we mixed sand in well-defined proportions with the eutectic binder. Mechanical tests were carried out.

For the compression test of the binder and sand mixture, the preparation of a test specimen is necessary. The size shall meet the standards of the test specimens. Our specimen is cylindrical in shape and the height must be twice as large as the diameter according to NFP 18406. The results of the compression tests are summarized on the following scale (Table 3 ).

Table 3. Results Compression test for different sandbinding composition

\begin{tabular}{lcccc}
\hline $\begin{array}{l}\text { Sand quantity } \\
{[\mathrm{g}]}\end{array}$ & 75 & 116 & 200 & 450 \\
\hline $\begin{array}{l}\text { Proportion \% } \\
\text { [agglomerate }-\end{array}$ & $60-40$ & $70-30$ & $80-20$ & $90-10$ \\
$\begin{array}{l}\text { binder] } \\
\text { Split up load }\end{array}$ & 22,60 & 22,73 & 17,27 & 3,76 \\
{$[\mathrm{kN}]$} & & & & \\
$\begin{array}{l}\text { Split up } \\
\text { resistance }\end{array}$ & $23,50^{*}$ & $23,60 *$ & 17,96 & 3.91 \\
{$[\mathrm{MPa}]$} & & & & \\
\hline
\end{tabular}

The breaking strength decreases with the decrease in the amount of the binder in the mixture. It can then be said that the binder plays a very important role for a structure.

We also carried out a wear test of our product at the MADAGASCAR National Laboratory for Public Works and Buildings (LNTPB). The test is in accordance with the standard NF EN 1342. The following figure shows a block after wearing test under a counterweight of $2 \mathrm{~kg}$ and with a drum rotation speed of $75 \mathrm{rpm}$ after a Minute test.

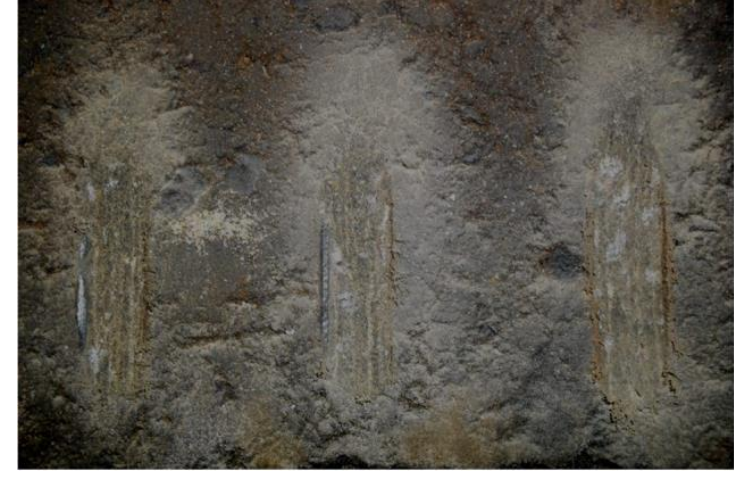

Fig. 5. The impression of the drum on the paving stone

The standard of the length of the impression for a concrete pave with these conditions is $25 \mathrm{~mm}$. During the test on our sample, the average length of the impression is $33 \mathrm{~mm}$.

The wear test standard for recycled paving is not yet available at LNTPB. But according to the findings of the responsible engineers and their analyzes with their experiments, the result is admissible.

\section{Conclusion and perspectives}

It is clear that the pavement manufacturing sector from plastic bags reveals opportunities that could be the vector of development of the country. The political challenge of each country in the third millennium is sustainable development. Sustainable development is about reducing spending and it is a new thought and idea.

On the social level, the creation of such a society combines with the creation of employment, which is a vector for development. The employment sector goes from the non-intellectual to the intellectual, such as the collection of waste plastic bags which gives an income to each collector, especially young people to improve their living conditions and support their needs while recycling a Material that causes problems.

On the environment, the recycling of the plastic bag reduces the proliferation of the plastic bag. As the years go by, the plastic bag can then disappear in nature because of the project.

On the infrastructure side, the construction of roads at lower cost gives the state an opportunity to develop and increase the means of linking each city to facilitate trade. Moreover, in the big cities, changing each lane that is not yet paved makes it easier for each individual to move during the rainy seasons.

Our country is developing the peoples, the purchasing power is very low. The price of the local paving made from cement is not affordable for the majority of the population. The launching of this project allows every family to improve the infrastructure at a lower cost.

Since it is a discovery of a new binder able to replace the cement from the economic point of view, the search for another finished product with this binder is conceivable. 
A numerical simulation of the thermomechanical and physico-chemical behavior of a composite using this binder in place of the polyester and epoxy resin is the result of our research.

By documenting, one can conclude that our process is the most profitable because of the saving of time with the process, the gain with the binder because using the same quantity of plastic bag our binder increases which is quite the opposite of the Other studies.

With the product realized may be Madagascar would be the cleanest and most developed country.

\section{Nomenclature}

Re : elasticity limit

$\mathrm{Rm}$ : tear resistance

E : module of Young

A : coefficient of elongation

\section{Keywords}

plastic bag, recycling, waste rich in carbonaceous element, sand, wet polymer binding

\section{References}

1. www.wikipedia.com/ les matières plastiques

2. Commentaire «les sacs plastiques: un vrai fléau», $<$ URL :http ://les-sacs-en-plastiques-un-vraifléau.html $>$

3. www.capsciences.net/upload/la_synthese_des_plastiques.pdf

4. www.wikipedia.com/ polyéthylène

5. www.achats-responsables.ch/pdf/LeGuide/.../D03Matieres_plastiques.pdf.

6. fsi.univ-tlemcen.dz/cours/TD-DREX-GORISSE.pdf

7. www.wikipedia.com/ la transition vitreuse

8. journaldumali.com: par Modibo FOFANA, le 05/02/2010,le recyclage de déchets plastiques, une solution écolo-citoyenne

9. www.ac-nancy-metz.fr

10. http://www.xr6805.fr/sti2d/courses/0data/et232_pack /STI2D_et236_proprietes_mecaniques.pdf

11. http://iutgc.bethune.free.fr

12. http://iut-tice.ujf-grenoble.fr

13. https://energypedia.info/wiki

14.Callister WD,Science et génie des matériaux, Edition Dunod

15.R.BASQUIN, Mécanique 2ème Partie, Librairie Delagrave

16. Dr. George W. Roberts, Dr. Saad A. Khan and Joan Patterson, North Carolina State University, "Researchers Develop New Plastic Recycling Process." ScienceDaily. ScienceDaily, 16 April 2003.

17. Lotfi, Ahmad. "Plastic Recycling" [online] available at : <http://www.lotfi.net/recycle/plastic.html $>$ 